MINIMAL LOSS OF GENETIC DIVERSITY AND NO INBREEDING DEPRESSION IN BLUEFLAG IRIS (IRIS VERSICOLOR) ON ISLANDS IN THE BAY OF FUNDY

\begin{tabular}{|r|l|}
\hline Journal: & Botany \\
\hline Manuscript ID & cjb-2016-0004.R2 \\
\hline Manuscript Type: & Article \\
\hline Date Submitted by the Author: & 15-Mar-2016 \\
\hline & $\begin{array}{l}\text { Wheelwright, Nathaniel; Bowdoin College, Biology } \\
\text { Begin, Elise; Colby College } \\
\text { Ellwanger, Claire; Bowdoin College } \\
\text { Stone, Jumuel; Bowdoin College }\end{array}$ \\
\hline Keyword: & blueflag iris, inbreeding depression, hand-pollination, islands \\
\hline
\end{tabular}


Wheelwright et al. - No inbreeding depression in blueflag iris

\title{
MINIMAL LOSS OF GENETIC DIVERSITY AND NO INBREEDING DEPRESSION \\ IN BLUEFLAG IRIS (IRIS VERSICOLOR) ON ISLANDS IN THE BAY OF FUNDY
}

\author{
Nathaniel T. Wheelwright ${ }^{1,6}$, Elise Begin ${ }^{2}$, Claire Ellwanger ${ }^{3}$, \\ Samuel H. Taylor ${ }^{4}$, and Judy L. Stone ${ }^{5}$
}

${ }^{\mathbf{1}}$ Department of Biology, Bowdoin College, Brunswick, ME, USA 04011

${ }^{2}$ Department of Biology, Colby College, Waterville, ME, USA 04901; elise.begin@gmail.com

${ }^{3}$ Department of Biology, Bowdoin College, Brunswick, ME, USA 04011; cf.ellwanger@gmail.com

${ }^{4}$ Department of Biology, Bowdoin College, Brunswick, ME, USA 04011; smuel.tylor@gmail.com

${ }^{5}$ Department of Biology, Colby College, Waterville, ME, USA 04901; jstone@colby.edu

${ }^{6}$ corresponding author: nwheelwr@bowdoin.edu; tel: (207) 725-3583; fax: (207) 725-3405 


\begin{abstract}
Isolated island plant populations founded by few individuals are often characterized by decreased genetic variation and increased inbreeding. Our aim was to measure population genetic diversity and inbreeding depression in blueflag iris (Iris versicolor L., Iridaceae), a native allotetraploid, on islands in the Bay of Fundy, Canada. Hand-pollination experiments (inbreeding, within-site outbreeding, between-island outbreeding) on Kent Island, New Brunswick revealed no evidence for inbreeding depression across a broad array of morphological, physiological and life history traits. Leaf tissue samples collected from three mainland sites and 10 islands in the Bay of Fundy and genotyped using three microsatellite primer pairs showed that island populations were less genetically diverse than mainland populations. Island populations were genetically distinct from each other, indicating a bottleneck effect associated with colonization and continued isolation. Nonetheless, substantial genetic variation was maintained at the population level. Polyploidy and a history of self-fertilization may allow Iris versicolor to avoid inbreeding depression in isolated populations. Our study supports Anderson's (1936) original hypothesis that substantial genetic diversity can be preserved within polyploid species even with extensive inbreeding.
\end{abstract}

Key words: blueflag iris; colonization; hand-pollination; inbreeding depression; Iris versicolor; islands. 


\section{INTRODUCTION}

Colonization is a key process for plant populations on the leading edge of an expanding range and in patchily-distributed habitats such as islands (Levin, 2000). Because island populations are usually established by relatively few individuals, colonization typically results in a genetic bottleneck and founder effects. In addition, island population sizes are often small so genetic drift can erode the subset of alleles surviving the initial bottleneck (Barrett, 1996). As a consequence, populations on small remote islands are expected to have lower genetic diversity than mainland populations (Barrett, 1996; Franks, 2010). Moreover, marginal climatic or soil conditions or the scarcity of pollinators on islands may present ecological challenges to plant populations, which can further diminish genetic variation (Barrett, 1996).

Baker (1955) predicted that self-compatible plants would have an advantage in colonizing isolated habitats because of their ability to reproduce where mates or pollinators are scarce. Available evidence largely supports Baker's prediction: self-compatibility is more common for island floras than mainland floras (Barrett, 1996; Crawford et al., 2011). In addition, peripheral populations frequently have higher incidences of selfing than central populations (Stebbins, 1957; Busch, 2005; Barrett et al. 1989, Moeller and Geber, 2005). These lines of evidence do not exclude the possibility that increased selfing evolved following colonization, rather than preceding and facilitating it (Cheptou, 2011). Nonetheless, at least one study has found evidence that self-fertilization served as a filter for successful island colonization (Schueller, 2004). Selfing plants may also possess an advantage in colonization because of their proclivity for tolerating genetic bottlenecks. Highly inbreeding taxa often purge their genetic load due to exposure of deleterious recessive alleles in homozygous state (Husband and Schemske, 1996; 
Winn et al., 2011). Selfing could therefore be a preadaptation for colonization not only because it provides reproductive assurance but also because its attendant elimination of genetic load staves off inbreeding depression in small populations (Glémin et al., 2003; Pujol et al., 2009).

Polyploidy is also associated with colonization of isolated habitats, possibly because it confers resistance to inbreeding depression (Stebbins, 1950, Levin, 2002, Pandit et al., 2011; te Beest et al., 2012). The extent to which polyploids suffer from inbreeding depression depends in part on whether they are auto- or allopolyploids (Lande and Schemske, 1985; Husband et al., 2008). Autopolyploids, which combine genomes of conspecific parents, retain higher heterozygosity upon inbreeding than their diploid progenitors because of the multiple combinations by which diploid gametes can produce heterozygous progeny (Soltis and Soltis, 2000). Allopolyploids, formed through a process of interspecific hybridization, also maintain high levels of genetic diversity because the original parental genomes are typically nonrecombinant, which can lead to fixed heterozygosity (Soltis and Soltis, 2000). In practice, many species fall somewhere between these two extremes. Empirical evidence on inbreeding depression in polyploids is still scarce, with some but not all studies showing decreased inbreeding depression in polyploids compared to diploid relatives (Husband and Schemske, 1997; Johnston and Schoen, 1996; Rosquist, 2001; Barringer and Geber, 2008; Husband et al., 2008).

Blueflag iris (Iris versicolor) is a classic example of a selfing allotetraploid species. Anderson (1936) argued that $I$. versicolor arose from one or more crosses between the northern $I$. setosa $(2 \mathrm{n}=38)$ and the southern Appalachian I. virginica $(2 \mathrm{n}=70-72)$. Recent molecular work has confirmed this hypothesis (Lim et al., 2007). Examining progeny arrays, Anderson (1936) 
determined that sexual reproduction in I. versicolor occurs primarily through self-fertilizion and concluded that $I$. versicolor consists of a series of largely independent populations inhabiting a "youthful" region that had become available for colonization since the retreat of the glaciers. The range of $I$. versicolor extends from northern Virginia and the upper Midwest to the Maritime provinces of Canada, with dense populations, each with one to several thousand clones (Anderson, 1936). Seeds float readily, and populations occur along the St. Lawrence River system (Anderson, 1928) and on islands in the Bay of Fundy, Canada, where field studies have reinforced Anderson's description of I. versicolor as a highly selfing species (Kron et al., 1993; Zink and Wheelwright, 1997).

In this study, we used I. versicolor as a model to address questions about inbreeding depression, heterosis and the population genetic consequences of colonization by a selfing, polyploid species (Husband et al., 2008). Selfing and polyploidy may have contrasting effects on the population genetic consequences of colonization, which we hoped our experiments would elucidate. Selfing in small populations can cause inbreeding depression to decline while simultaneously causing fixation of mildly deleterious mutations (Glémin et al., 2003; Roze and Rousset, 2004). In such cases, crossing between distinct populations would enhance fitness, even in the absence of overdominance (Charlesworth and Barrett 1991). On the other hand, if allopolyploidy maintains fixed heterozygosity, crossing between distinct populations should be less likely to enhance fitness.

Our goal was to examine inbreeding depression in the context of the genetic structure of island populations by (1) carrying out a series of controlled crosses in I. versicolor to estimate performance of progeny resulting from open pollination, self-pollination, outcross-pollination 
from the same island, and outcross-pollination from another island, and (2) genotyping $16 I$. versicolor populations on the mainland and islands of different sizes throughout the Bay of Fundy to assess the extent to which colonization was associated with loss of genetic diversity, increased genetic differentiation, or isolation by distance. The experiments in this study extend previous work on I. versicolor (Zink and Wheelwright, 1997, Wheelwright et al., 2006). We investigated a wide array of morphological and proximate physiological traits that have potential to influence life history, including traits not expressed until adulthood (Johnsen et al. 2003, Heshel et al. 2005).

We predicted that (1) hand-crossing experiments on island populations of I. versicolor would reveal low levels of inbreeding depression given the populations' history of selffertilization. We also predicted that bottlenecks associated with island colonization and subsequent isolation would be associated with (2) substantial genetic differentiation among island populations, but that (3) considerable genetic diversity might be maintained in these island populations, possibly as a result of polyploidy.

\section{MATERIALS AND METHODS}

Study system - Our study sites were located on islands and on several mainland sites in the Bay of Fundy, Canada (Fig. 1). The islands where we sampled I. versicolor have been isolated from the mainland and, in most cases, each other since at least the time of lowest sea level during glaciation 9500 years ago (see Shipp et al., 1991, NOAA $(2011,2013)$. On each island, we

sought wet areas where irises occurred and where individual clones could be distinguished (see 
below). Pollination experiments were carried out on Kent Island, New Brunswick $\left(44.582^{\circ} \mathrm{N}\right.$, $\left.66.756^{\circ} \mathrm{W}\right)$, with pollen collected from adjacent Hay and Sheep Islands. Many insect pollinators doubtless move between the three islands (one can walk to Hay Island at low tide, and to Sheep at extreme low tide) (Fig. 1). Like most islands in the Bay of Fundy, Kent, Hay and Sheep Islands are subjected to strong winds and thick fog; cool temperatures year-round produce a boreal climate, flora and fauna. The species richness of flower-visiting insects is only about $15 \%$ of the mainland (Wheelwright et al., 2006).

Leaf tissue samples were collected from Kent, Hay and Sheep Islands, as well as from seven other islands in the Bay of Fundy between Cutler, Maine and Black's Harbour, Nova Scotia, and three mainland sites (Fig. 1). We sampled from two locations on the large island of Grand Manan and three locations on Kent Island. With the exception of Campobello Island, all of the islands lay more than $17 \mathrm{~km}$ offshore. We considered Campobello to be effectively a mainland site because of its connection to the mainland by a bridge, close proximity to the mainland, and large size.

Reproductive biology of Iris versicolor - Iris versicolor reproduces sexually via showy insectpollinated flowers and asexually via rhizomes. Seeds are dispersed by gravity, strong winds, or water. Individual ramets bear 1-4 flowers. On Kent Island, flowers begin to open in mid- to late June. Flowers are protandrous, with anthers dehiscing 12-24 h after the flower opens. Approximately $24 \mathrm{~h}$ later, small flaps on the underside of the tip of each of three stylar arms reflex downwards to expose the stigmas (Proctor and Yeo, 1973; Kron et al., 1993; Zink and Wheelwright, 1997). Hand-pollination experiments have confirmed that $I$. versicolor is capable 
of autonomous self-pollination, although insect pollinators enhance seed set (Kron et al., 1993; Zink and Wheelwright, 1997). Although I. versicolor is principally visited by bumblebees (Bombus spp.) in mainland populations (Kron et al., 1993), most visitors on Kent Island are seaweed flies (Coelopidae) (Zink and Wheelwright, 1997).

Hand-pollination experiments - All pollination experiments were conducted on Kent Island in June and July, 2011. We selected two open wet sites separated from each other by about $1 \mathrm{~km}$ of grassy fields and spruce-fir (Picea rubens-Abies balsamea) forest. Within each site, 30 different iris clones, each with at least 16 developing flowers on different ramets (to provide ample sample sizes for all pollination treatments), were haphazardly selected. The boundaries of individual clones were recognizable by the dense clumping of their ramets and spatial isolation from other clusters of ramets, and by each clone's relatively uniform distinctive flower color and leaf size and shape, even when they shared the same microhabitat (pers. obs.). Although we did not use multilocus genotyping to verify the identify of clones, we only included in the sample unambiguous clones (i.e., ramets presumed to be of the same genet) that were separated from other clones by at least $5 \mathrm{~m}$ of grass and herbaceous vegetation.

Within clones, each virgin flower was haphazardly assigned to one of three treatments: (1) control (open pollination by insects), (2) inbreeding (hand-pollination using pollen from a different flower from the same clone), and (3) between-island outbreeding (hand-pollination using pollen from a clone from Grand Manan, Hay, or Sheep Island). Each treatment was replicated on four flowers within each clone at each site $(\mathrm{N}=2$ sites $\mathrm{x} 30$ clones $\mathrm{x} 3$ treatments $\mathrm{x}$ 4 replicates $=720$ flowers). We also included an additional treatment, (4) within-site outbreeding 
(hand-pollination using pollen from a different clone within the same site), but because the within-site outbreeding treatment was delayed a week due to time and weather constraints, we analyze those data separately. The sample size for all four treatments was 933 flowers.

Hand-pollinations involved collecting a mature anther in the morning and, within 1-8 $\mathrm{h}$, brushing it over the stigma of another flower until the stigma was densely covered with pollen. The two Kent Island sites differed slightly in flowering phenology so hand-pollinations were started 2-3 days later at the South site. To ensure that hand-pollinated flowers did not receive additional pollen dropped from their own anthers or from insects transporting pollen from other flowers, we used scissors to cut off all anthers, sepals, and petals before the stigma was exposed, which made the flowers less conspicuous and attractive to pollinators and the stigmas less accessible because insects could not easily land on the flowers. In previous studies (Wheelwright et al., 2006, Zink and Wheelwright, 1997), we had set up mesh cages over individual flowers to exclude pollinators. However, removing flower parts allowed us to increase our sample size greatly and avoided the potential problem of the cages altering the microclimate or interfering with the normal development of the fruit capsule. To verify that removal of floral parts prevented insect pollination and autonomous selfing, we selected 50 flowers in a separate plot, leaving half as controls and removing anthers, sepals, and petals from the other half. All control flowers set fruit, whereas none of the manipulated flowers did. One day after the flowers had opened we also examined, under a dissecting scope, 30 additional flowers whose anthers, sepals, and petals had been removed. We found no pollen grains on their stigmas. 
Fruit set, seed counts and germination - On 21 July 2011, we censused all 933 experimental flowers, recorded whether fruits had set or aborted, and measured the length of developing capsules to $1 \mathrm{~mm}$ using dial calipers. By 17 September 2011, herbivory by muskrats (Zibetheca) and other factors unrelated to pollination success had reduced our sample, although capsule mortality was independent of treatment (mortality ranged from 10.3 to $18.3 \%$ in different treatments). Of 800 surviving flowers, 549 (68.6\%) produced mature capsules. We harvested all mature capsules, measured their lengths, and stored them indoors at $18^{\circ} \mathrm{C}$ for two months, after which seeds were removed and photographed using Qcapture software. The program CellProfiler was used to count the number of viable and aborted seeds per capsule and to estimate their relative size by calculating the area of each seed (based on number of pixels). Viable seeds could be distinguished by their large size, fleshiness, and pigmentation; aborted seeds and unfertilized ova were much smaller and appeared desiccated (Kron et al., 1993). Seeds from each capsule were then placed in separate paper coin envelopes and stored in double plastic bags at $3.4^{\circ} \mathrm{C}$ prior to use in germination assays.

Six months later we selected 20 mature seeds from each of 142 capsules to test for germination. Because of space limitations, we could only germinate a subset of our overall sample. Capsules were chosen haphazardly within treatments and clones, with the aim of having roughly equal representations of each treatment and clone. Seeds were placed in individual Petri dishes lined with filter paper and watered every three days with $2 \mathrm{ml}$ of distilled water. Petri dishes were stored at $18^{\circ} \mathrm{C}$ for four weeks then placed in a growth chamber on a 12-hour temperature schedule of $18.3^{\circ} \mathrm{C}$ during the night and $23.8^{\circ} \mathrm{C}$ during the day. Seeds were subsequently monitored for germination every 2-4 days through June 2012. 
Greenhouse protocols and physiological measurements - Seedlings $\left(\mathrm{F}_{1}\right)$ from the germination experiments were transplanted during the summer and fall of 2012 and grown in potting soil in $12 \times 12 \mathrm{~cm}$ pots during the winter of $2012-2013$ in a heated greenhouse $\left(25^{\circ} \mathrm{C}\right)$ with Supplementary lighting (16 L:8 D, $100 \mu \mathrm{mol} \mathrm{m} \mathrm{m}^{-2}$ at bench level), which prevented plants from going fully dormant. Plants were checked daily and watered when necessary to maintain damp soil. Limited greenhouse space and the need to replicate physiological measurements led us to subdivide the sample for germination experiments. Plants were drawn from the two maternal clones that had sufficient samples of seedlings from each treatment, with one clone from the South site (S2) and one from the West Beach site (WB5). Within each clone we measured 1-3 seedlings from 2-4 seed capsules per pollination treatment (total: 61 seedlings from 25 capsules; in Tables S4 and S5, we present analyses including three additional clones which represented some but not all of the treatments).

In April 2013, we counted the number of leaves on each $F_{1}$ plant and measured the length (cm, using a ruler), width and thickness ( $\mathrm{mm}$, using dial calipers) of their longest leaves. During April and May, we quantified two aspects of photosynthetic efficiency that can be rapidly and effectively measured using chlorophyll fluorescence. The maximum quantum yield, $\mathrm{F}_{\mathrm{v}} / \mathrm{F}_{\mathrm{m}}$, measures the maximum (unstressed, dark-adapted) capacity of photosynthetic machinery to absorb light. The effective quantum yield, $\Phi_{\text {PSII }}$, measures the efficiency with which absorbed light is used during photosynthesis (see Supplementary Material Online for additional details).

Finally, although this study was not designed to test for differences between treatments in overwinter survival and flowering under natural conditions, we conducted a pilot project in 
which 24 haphazardly selected $F_{1}$ plants from both inbred and outbred treatments were transplanted in September 2012 to the edge of a rural pond in Brunswick, Maine and monitored over several additional years.

Inbreeding depression: measurements and statistical analyses - The significance of absolute differences among pollination treatments was compared using linear mixed effects models ( $\mathrm{arm}$ package in R: Gelman and Su, 2013) (see Supplementary Material Online). Generalized linear mixed models were used where appropriate; a Poisson distribution was used to model the number of leaves per plant (counts of which ranged from 8 to 45 leaves and were strongly leftskewed) and a binomial distribution was used to model proportional data (proportions of: flowers that set fruit; seeds matured; seeds germinated). To account for overdispersion, generalized linear models of the proportion of seeds matured, proportion of seeds germinated, and number of leaves per plant included clone as a random effect. Estimates of breeding effects were calculated as relative performance (RP; Ågren and Schemske, 1993). RP ranges from -1 to 1, with negative values indicating advantages to inbred individuals and positive values indicating inbreeding depression. RP is equivalent to $\partial=1-\mathrm{w}_{\mathrm{s}} / \mathrm{w}_{\mathrm{o}}$ where inbreeding depression is observed and has the advantage of equally weighting cases in which outbred groups perform more poorly, which occurred in many cases in our analysis. Because within-site outbreeding treatments were begun one week later than other treatments we represented $w_{o}$ using the less conservative betweenisland outbreeding treatment, which we expected to show the least inbreeding depression. 
Tissue sampling and genotyping - During the last week of June 2011, we collected iris leaf tissue samples from the three mainland sites and 10 islands. Although we did not attempt to count the number of clones or ramets at each site, blueflag iris was common and population densities roughly equal on all of them; even the smallest islands had hundreds or thousands of clones. At each site we identified 30 distinct clones (for descriptions of how clones were determined, see Hand-Pollination Experiments). From each clone we collected a $2 \mathrm{~cm}$ x $2 \mathrm{~cm}$ tissue sample from the distal third of the longest fully-formed leaf. Leaf samples were immediately put in separate coin envelopes with silica gel desiccant, then stored in sealed plastic bags with additional silica gel until processing. Sampling at each site was completed within 1-2 h.

For microsatellite primer development, dried leaf samples $(\sim 100 \mathrm{mg})$ from seven plants from Sheep, Kent, and Hay Islands were sent to ATG Genetics (Comox, British Columbia). We evaluated 16 of the 28 loci identified based on the reported quality and consistency of amplification. In addition, we tested nine expressed sequence tags for simple sequence repeats (EST-SSRs) (Tang et al., 2009). Of the 22 primer pairs that produced amplicons, eight were invariant across 16 samples from different islands and were not used further. Fourteen of the pairs generated chromatograms that were variable, but 11 of these were not possible to score because they either amplified poorly or generated complex chromatograms that were inconsistent across replicate runs, making it difficult to reliably identify fragment lengths. Three primer pairs consistently amplified easily interpretable peaks showing variation among individuals (tet4, tet9 and IM200; see supplementary Table S1). DNA extraction and PCR amplification followed standard procedures. PCR products were loaded onto an Applied Biosystems 3130 Genetic 
Analyzer. Peaks were called using GeneMapper, and chromatograms were scored manually (see Supplementary Material Online).

Genotyping and population genetic analysis - In tetraploid plants such as I. versicolor, a chromatogram with two peaks could represent two copies each of two alleles, or one copy of one allele and three of the other allele. Additionally, amplified fragments could be homologous (i.e., from the genome of the same progenitor), or homeologous (from loci of the two different progenitors). Because of these sources of ambiguity, we treated the markers as dominant, scoring peaks as either present or absent. Genetic diversity was assessed by the number of distinct alleles observed and the percentage of observed fragment lengths that were polymorphic within populations.

Diversity among samples from island and mainland populations was compared using the Wilcoxon rank sum test. The relationship between diversity and distance from the mainland was evaluated using a Spearman rank correlation (StataCorp, 2011). Population genetic analyses were conducted using the GenAlEx 6.501 software package (Peakall and Smouse, 2012). Genetic distances were founded on binary comparisons across all observed fragment lengths. The genetic differentiation of mainland and island populations was compared using Analysis of Molecular Variance (AMOVA), with mainland populations representing one region and the islands another. We calculated $\Phi_{\mathrm{PT}}$, the binary analog of $\mathrm{F}_{\mathrm{st}}$, to evaluate pairwise comparisons of genetic diversity among populations (Excoffier et al. 1992), and a Mantel test to determine whether there was a correlation between genetic and geographic distance. Significance for the 
AMOVA and Mantel tests was determined by 999 permutations (see Supplementary Material Online for additional details).

\section{RESULTS}

Hand-pollination experiments - Hand-pollination experiments revealed no evidence of inbreeding depression or heterosis. Comparing all four treatments - open-pollinated (control), inbreeding (self-pollinated), within-site outbreeding, or between-island outbreeding — there was evidence for significant variation among levels but this was not associated with lower mean fruit set for the selfing treatment. Indeed, average fruit set tended to be higher for selfed flowers than for the other treatments (Fig. 2; Table 1). There were no significant site effects (Table 1). Given that these measures of fitness could have been affected by the fact that the within-site outbreeding treatment was applied a week later than the other three treatments, we present analyses below omitting the within-site outbreeding treatment.

Among the open-pollinated, inbreeding, and between-island outbreeding treatments, the only trait for which there was a significant treatment effect was the proportion of flowers that set fruit, which was actually highest for self-pollinated plants (Fig. 2; Table S2). Seed germination did not vary by treatment (Fig. 2; Table S2).

For traits measured on $F_{1}$ individuals grown in the greenhouse - photosynthetic efficiency $\left(\Phi_{\mathrm{PSII}}, \mathrm{F}_{\mathrm{v}} / \mathrm{F}_{\mathrm{m}}\right)$ and leaf number and size (length, width, and thickness) — no significant treatment effects were detected (Fig. 3) whether the within-site outbreeding treatment was included (Table 1) or excluded (see supplementary Table $S 2$; note that owing to the extended period of growth in 
the greenhouse, measures of performance in $F_{1}$ progeny would be unlikely to have been affected by the delay in the within-site outbreeding treatment). The over-winter survival of $F_{1}$ plants planted in the field also did not appear to depend upon treatment. Although our sample size was small ( $\mathrm{N}=6$ per treatment) and none of the two-year-old $\mathrm{F}_{1}$ plants set fruit, the same proportion of plants $(17 \%)$ produced flowers in each treatment.

Relative performance (RP) was rarely significantly different from 0 , ranging from -0.112 to 0.184 for traits from the Kent Island populations, and from -0.039 to 0.152 for the $F_{1}$ progeny in the greenhouse (see supplementary Table S3). RP for 9 of 12 traits measured in this study fell in the range -0.1 to 0.1 ; power calculations using standard deviations from our experiments indicated that to obtain significant differences in that range, we would have needed at least to double our sample size for most traits to around 2000 flowering ramets, compared with the 933 we used to initiate our experiment. The sole significant difference in RP across our experiments was in fruit set at the South site, where inbred crosses had a significant advantage $(\mathrm{RP}=-0.21)$. Although inbred crosses also had an advantage in fruit set at the West Beach $(\mathrm{RP}=-0.02)$ that advantage was not significant, nor was the average RP for fruit set across the two populations on Kent Island (-0.11). These results for RP of fruit set are consistent with the marginally nonsignificant site $\times$ treatment interaction in our ANOVA analysis (see supplementary Tables S3-5).

Molecular genetic diversity and differentiation - Each primer pair amplified 9-15 distinct fragment lengths (Table S1; online supplementary material). The number of fragments per primer pair per individual ranged from 1-6, with intermediate numbers of fragments most common. Fragment length distributions were generally consistent with the segregation of two 
homeologous loci, one with 1-2 alleles per individual, the other with 1-4 alleles per individual. Depending upon the primer pair, $0-5 \%$ of individuals amplified for only a single fragment, due to inconsistent amplification or a null allele. A large number of different genotypes per primer pair were generated, ranging from 65-93 across the 320 individuals assayed (Table S1). Of the 312 individuals for which we obtained genotypes for all three primer pairs, a remarkable 303 showed distinct multi-locus genotypes.

The process of colonization was associated with a loss of genetic diversity; the level of polymorphism was lower for island populations than for mainland populations $(59.5 \% \mathrm{vs}$. 72.6\%, respectively; Table 2; Wilcoxon rank sum test, $z=2.374 ; \mathrm{n}_{1}=3 ; \mathrm{n}_{2}=13, P=0.018$ ). Among island populations, neither island size nor distance from the mainland was a significant predictor of genetic diversity (Fig. 4; Table 2). Although island populations showed lower polymorphism, they nevertheless maintained substantial genetic variation, with an average of 7.4 alleles per primer pair in comparison with 8.8 for mainland populations (Table 2). Molecular analysis of variance (AMOVA) revealed that only $4 \%$ of overall genetic variation was attributable to differentiation between mainland and island populations, $10 \%$ was distributed among populations within island or mainland regions, and $86 \%$ of genetic variation was maintained within populations.

Populations were strongly diverged. Of the 120 pairwise comparisons of genetic distance between populations, 83 were highly significantly different $(P \leq 0.001), 22$ were significantly different $(0.001<P \leq 0.01)$, and 13 were marginally different $(0.01<P \leq 0.10)$ (see supplementary Table S6). A Mantel test showed a significant relationship between genetic and geographic distance among sampled $I$. versicolor populations $(\mathrm{N}=16, r=0.648, P=0.002)$. 
However, this significant relationship becomes marginal with the removal of distant, small Machias Seal Island $(\mathrm{N}=15, r=0.194, P=0.099)$.

\section{DISCUSSION}

Iris versicolor on Kent Island suffered no measurable inbreeding depression for a broad array of reproductive, morphological and physiological traits. Seed set, number and proportion of viable seeds, seed size, germination rate, seedling growth rate, photosynthetic efficiency, and overwinter survival did not differ between flowers hand-pollinated with pollen from the same clone versus flowers outcrossed with pollen from a different site or open-pollinated (control) flowers. These results confirm and extend previous findings of a lack of inbreeding depression on early-acting traits in Kent Island I. versicolor (Wheelwright et al., 2006; Zink and Wheelwright, 1997), and, importantly, quantify the impact of inbreeding on traits acting later in life. Unexpectedly, flowers outcrossed with pollen from distinct clones at the same site (withinsite outbreeding treatment) showed the lowest seed production and quality. Although this could indicate outbreeding depression, it could be an artifact of the hand-pollinations for the within-site outbreeding treatment being started a week after the other treatments, with the lower reproductive success caused by minor differences in phenology or in weather conditions. In fact, when we repeated the analysis excluding the within-site outbreeding treatment, selfed flowers appeared to have higher seed set than outcrossed flowers. Nonetheless, without a proper withinsite outbreeding treatment, we cannot be certain what mechanisms lead to the lack of difference between the selfing and the between-population outbreeding treatments, since the fitness of 
outbreeding between populations could reflect the combination of both heterosis and outbreeding depression. In light of the close proximity of the Kent, Hay and Sheep Islands, outbreeding depression seems unlikely. Note also that the delay in the within-site outbreeding treatment should be less of a concern for the measures of physiological performance. In any event, comparisons of the multiple phenotypic traits of self-pollinated flowers with flowers from each of the other three treatments provide no evidence for inbreeding depression in this population.

Slight differences between the two Kent Island sites as well as significant treatment $\times$ site effects could have been due to distinct physical or ecological conditions, or to small differences in the timing of the experiments. A delay in beginning the within-site outbreeding treatment likely explains reduced seed numbers and capsule sizes in that treatment. In this system, minor differences in environmental conditions may have much larger influences on performance than mating patterns.

Our findings are consistent with other studies carried out on predominantly selfing species, which frequently show little or no inbreeding depression, especially for early life stages (Husband and Schemske, 1996; Winn et al., 2011). In their review of inbreeding depression, Winn et al. (2011) included 13 species with selfing rates greater than 0.8. Across these species, the median fitness of selfed relative to hand-outcrossed progeny was 0.91 for seed production, 0.95 for germination, 0.99 for juvenile survivorship, and 0.90 for fecundity. In our study, relative fitness of selfed to outcrossed progeny for I. versicolor ranged from 0.90 for seed germination to 1.03 for the number of mature seeds. Relative performance based on $F_{1}$ photosynthetic efficiency and plant size also fell largely within this range. 
The limited available evidence suggests that allopolyploidy is associated with reduced inbreeding depression (Rosquist, 2001; Barringer and Geber, 2008; but see Johnston and Schoen, 1996). Husband et al. (2008) found that allopolyploids have a significantly higher selfing rate than autopolyploids, which the authors attributed to the protection provided against inbreeding depression in allopolyploid species. Allopolyploids can retain fixed heterozygosity upon selfing because homoeologous loci may pair independently during meiosis. In our initial screening for variable markers, we identified eight loci that amplified the two same fragments across samples from 16 islands, a pattern consistent with fixed heterozygosity with alternative alleles at each of the two homoeologous loci. Amplification profiles for the markers that we scored suggest segregation of alleles at two homoeologous loci, one having up to two alleles per locus and the other up to four alleles per locus. These results are consistent with the origin of I. versicolor as an allopolyploid formed from diploid I. setosa and tetraploid I. virginica (Anderson, 1936). Nevertheless, recombination of some homoeologous chromosomes must occur, because Anderson (1936) reported observing multivalents in both I. virginica and I. versicolor. In such cases, inbreeding depression can decrease with selfing as in diploids or, alternatively, it can increase with selfing if the expression of nearly recessive deleterious mutations is a function of copy number (Ronfort 1999). In I. versicolor, fitness-governing loci may not behave as homologous loci or may not be characterized by dosage-dependent fitness effects.

Absence of inbreeding depression in a selfing, polyploid, colonizing plant could be attributed to purging associated with inbreeding (Lande and Schemke, 1985), maintenance of heterozygosity associated with polyploidy (Soltis and Soltis, 2000), or the fixation of deleterious alleles during the genetic bottleneck that accompanies colonization (Pujol et al. 2009). We 
cannot disentangle all of these possibilities, but we can distinguish the first from the third by examining outcross progeny fitness from between-island crosses. Heterosis for inter-island crosses would reveal stochastic fixation of different sets of deleterious recessive alleles in different colonization events on different islands, whereas lack of heterosis supports purging of deleterious alleles. We found no evidence for heterosis, which could be a result of the proximity of the three islands or the minimal impact of colonization bottlenecks on fitness-affecting loci. This result is consistent with our molecular genetic results, in which we found some decline in genetic diversity associated with island colonization, but no consistent pattern of increased isolation with distance from the mainland. AMOVA indicated that the great majority of genetic variation was maintained within populations; less than $5 \%$ of the total variation was attributable to differentiation between mainland and island populations.

Our finding of high genetic diversity maintained within populations is consistent with Anderson's (1936) impression that I. versicolor consists of a series of largely autonomous inbred lines with diversity maintained within and between populations by the sheer number of clones. He found striking morphological differences among colonies even within the same region, noting that "each little colony is a more or less independent evolutionary unit" (Anderson, 1936; p.493). Anderson also found, as we did, little evidence for isolation by distance, saying "In spite of the fact that the colonies measured extend from ... Maryland to the North Woods in the case of $I$. versicolor, there is practically no evidence of regional differentiation; that is, the formation of morphologically distinct geographical subspecies within (the range)" (Anderson, 1928; p.295). I. versicolor does not possess any obvious mechanisms for long-distance seed dispersal, although Anderson (1928) noted that seeds do float readily. Proximity to other populations may reduce 
additional divergence following the initial colonization of islands in the Bay of Fundy; irises sampled on the isolated Machias Seal Island were by far the most genetically distinct from any of our other sampled populations.

A limitation of this study was our inability to develop co-dominant markers that could be used to estimate selfing rates from progeny arrays or inbreeding coefficients from adult tissues. Interpretation of genetic data is notoriously difficult in polyploid species (Dufresne et al., 2014). Some workers have been able to interpret dosage by intensity of allozyme bands or peak heights on microsatellite chromatograms (e.g., Esselink et al., 2004), but we were only able to score presence/absence of fragment lengths. We have begun to compare banding patterns in progeny arrays to determine whether a subset of fragments could be reliably used as co-dominant markers. This information would allow us to fully explore the implications of island colonization. It would be interesting to see whether islands with lowered pollinator abundance experience higher selfing rates and altered population genetic structure.

In conclusion, island populations of polyploid I. versicolor maintain genetic variation and avoid inbreeding depression in isolated island populations. Future studies could answer questions about ecological differences between mainland sites and islands of varying size and remoteness. For example, on isolated islands where the normal pollinators of I. versicolor are absent, are clones more likely to possess morphological features that promote autogamy? If populations on isolated islands are more genetically depauperate, are they more subject to inbreeding depression or heterosis than less isolated populations? Exploring how floral traits, pollination biology, and population genetic traits differ between sites will help us understand the causes and 
consequences of the colonization of islands and isolated mainland sites by species such as Iris versicolor.

\section{ACKNOWLEDGEMENTS}

The authors thank M. Acosta, J. Bateman, A. Boeke, J. Cook, P. Easton, A. Eichenwald, D. and J. Gannon, M. Gimond, R. Perez, and A. Short for help in the field, lab and greenhouse; D. Shutler for collecting iris samples in Nova Scotia; Manny Gimond for providing the base map; and B. Logan and M. Palopoli for comments on earlier versions of the manuscript. The authors declare no conflicts of interest. This work was supported by Bowdoin and Colby Colleges; a Colby-Bates-Bowdoin-Mellon Grant to NTW and JS; a National Science Foundation OPUS Award to NTW [0816132]; and grants from the National Institutes of Health to JS [NCRR 5P20RR016463-12; NIGMS 8 P20 GM103423-12]. This represents contribution no. 257 from the Bowdoin Scientific Station. 


\section{REFERENCES}

Anderson, E.A. 1928. The problem of species in the northern blue flags, Iris versicolor L., and Iris virginica L. Ann. Missouri Bot. Garden 15: 241-332.

Anderson, E.A. 1936. The species problem in Iris. Ann. Missouri Bot. Garden 23: 457-509.

Ågren, J., and Schemske, D.W. 1993. Outcrossing rate and inbreeding depression in two annual monoecious herbs, Begonia hirsuta and B. semiovata. Evol. 47: 125-135.

Baker, H.G. 1955. Self-compatibility and establishment after 'long-distance' dispersal. Evol. 9: 347-349.

Barrett, S.C.H. 1996. The reproductive biology and genetics of island plants. Phil. Trans. Roy. Soc. London Series B-Biol. Sci. 351: 725-733.

Barrett, S.C.H., and Charlesworth, D. 1991. Effects of a change in the level of inbreeding on the genetic load. Nature 352: 522-524.

Barrett, S. C.H., Morgan, M.T., and Husband, B.C. 1989. The dissolution of a complex genetic polymorphism: the evolution of self-fertilization in tristylous Eichhornia paniculata (Pontederiaceae). Evol. 43: 1398-1416.

Barringer, B.C., and Geber, M.A. 2008. Mating system and ploidy influence levels of inbreeding depression in Clarkia (Onagraceae). Evol. 62: 1040-1051.

Busch, J.W. 2005. The evolution of self-compatibility in geographically peripheral populations of Leavenworthia alabamica (Brassicaceae). Am. J. Bot. 92: 1503-1512.

Cheptou, P.-O. 2011. Clarifying Baker's Law. Annals Bot. 109: 633-641. 
Crawford, D.J., Anderson, G.J., and Bernardello, G. 2011. The reproductive biology of island plants. In D. Bramwell and J. Caujapé-Castells [eds.], The biology of island floras, 11-36. Cambridge University Press, Cambridge, UK.

Dufresne, F., Stift, M., Vergilino, R., and Mable, B. 2014. Recent progress and challenges in population genetics of polyploid organisms: an overview of current state-of-the-art molecular and statistical tools. Molec. Ecol. 23: 40-69.

Esselink, G.D., Nybom, H., and Vosman, B. 2004. Assignment of allelic configuration in polyploids using the MAC-PR (microsatellite DNA allele counting-peak ratios) method. Theor. Applied Genetics 109: 402-408.

Excoffier, L., Smouse, P.E., and Quattr, J.M. 1992. Analysis of molecular variance inferred from metric distances among DNA haplotypes: Application to human mitochondrial DNA restriction data. Genetics 131: 479-491.

Franks, S.J. 2010. Genetics, evolution, and conservation of island plants. J. Plant Biol. 53: 1-9.

Gelman, A., and Su, Y.-S. 2013. Data analysis using regression and multilevel/hierarchical models. R package version 1.6-06.01.

Glémin, S., Ronfort, J., and Bataillon, T. 2003. Patterns of inbreeding depression and architecture of the load in subdivided populations. Genetics 165: 2193-2212.

Heschel M.S., Hausmann, N., and Schmitt, J. 2005. Testing for stress-dependent inbreeding depression in Impatiens capensis (Balsaminaceae). Am. J. Bot. 92:1322-1329.

Husband, B.C., Ozimec, B., Martin, S.L., and Pollack, L. 2008. Mating consequences of polyploid evolution in flowering plants: Current trends and insights from synthetic polyploids. Int. J. Plant Sci. 169: 195-206. 
Husband, B.C., and Schemske, D.W. 1996. Evolution of the magnitude and timing of inbreeding depression in plants. Evol. 50: 54-70.

Husband, B C., and Schemske, D.W. 1997. The effect of inbreeding in diploid and tetraploid populations of Epilobium angustifolium (Onagraceae): implications for the genetic basis of inbreeding depression. Evol. 51: 737-746.

Johnsen, K., Major, J.E., and Maier, C. 2003. Selfing results in inbreeding depression of growth but not of gas exchange of surviving adult black spruce trees. Tree Physiol. 23:1005-8.

Johnston, M.O., and Schoen, D. J. 1996. Correlated evolution of self-fertilization and inbreeding depression: an experimental study of nine populations of Amsinckia (Boraginaceae). Evol. 50: 1478-1491.

Kron, P., Stewart, S.C., and Back, A. 1993. Autonomous self-pollination, and insect-mediated pollination in the clonal species Iris versicolor. Can. J. Bot. 71: 1503-1509.

Lande, R., and Schemske, D.W. 1985. The evolution of self-fertilization and inbreeding depression in plants. I. Genetic models. Evol. 39: 24-40.

Levin, D.A. 2000. The origin, expansion, and demise of plant species. Oxford University Press, Oxford, UK.

Levin, D.A. 2002. The role of chromosomal change in plant evolution. Oxford University Press, Oxford, UK.

Lim, K.Y., Matyasek, R., Kovarik, A., and Leitch, A. 2007. Parental origin and genome evolution in the allopolyploid Iris versicolor. Annals Bot. 100: 219-224. 
Moeller, D.A., and Geber, M.A. 2005. Ecological context of the evolution of self-pollination in Clarkia xantiana: population size, plant communities, and reproductive assurance. Evol. 59: 786-799.

National Oceanic and Atmospheric Administration, United States. 2011. Nautical Chart 13392: Grand Manan Channel, Southern Part.

National Oceanic and Atmospheric Administration, United States. 2013. Nautical Chart 13394: Grand Manan Channel, Northern Part.

Pandit, M.J., Pocock, M.J.O., and Kunin, W.E. 2011. Ploidy influences rarity and invasiveness in plants. J. Ecology 99: 1108-1115.

Peakall, R., and Smouse, P.E. 2012. GenAlEx 6.5: genetic analysis in Excel. Population genetic software for teaching and research-an update. Bioinformatics 28: 2537-2539.

Proctor, M., and Yeo, P. 1973. The pollination of flowers. Collins, London.

Pujol, B., Zhou, S.-R., Sanchez Vilas, J., and Pannell, J.R. 2009. Reduced inbreeding depression after species range expansion. Proc. Nat. Acad. Sci. 36: 15379-15383.

Ronfort, J. 1999. The mutation load under tetrasomic inheritance and its consequences for the evolution of the selfing rate in autotetraploid plants. Genetical Res. 74: 31-42.

Rosquist, R. 2001. Reproductive biology in diploid Anthericum ramosum and tetraploid $A$. lilago (Anthericaceae). Oikos 92: 143-152.

Roze, D., and Rousset, F. 2004. Joint effects of self-fertilization and population structure on mutation load, inbreeding depression and heterosis. Genetics 167: 1001-1015.

Schueller, S.K. 2004. Self-pollination in island and mainland populations of the introduced hummingbird-pollinated plant, Nicotiana glauca (Solanaceae). Am. J. Bot. 91: 672-681. 
Shipp, R.C., Belknap, D.F., and Kelley, J.T. 1991. Seismic-stratigraphic and geomorphic evidence for a post-glacial sea-level lowstand in the Northern Gulf of Maine. J. Coastal Res. 7: 341-364.

Soltis, P.S., and Soltis, D.E. 2000. The role of genetic and genomic attributes in the success of polyploids. Proc. Nat. Acad. Sci. 97: 7051-7057.

StataCorp. 2011. Stata statistical software: Release 12. College Station, Texas, USA.

Stebbins, G.L. 1950. Variation and evolution in plants. Columbia University Press, New York, USA.

Stebbins, G.L. 1957. Self-fertilization and population variability in the higher plants. Am. Nat. 91: 337-354.

Tang, S., Okashah, R.A., Cordonnier-Pratt, M., Pratt, L.H., Johnson, V.E., Taylor, C.A., Arnold, M.L., and Knapp, S.J. 2009. EST and EST-SSR marker resources for Iris. BMC Plant Biology 9: 72-82.

te Beest, M., Le Roux, J.J., Richardson, D.M., Brysting, A.K., Suda, J., Kubešová, M., and Pyšek, P. 2012. The more the better? The role of polyploidy in facilitating plant invasions. Annals Bot. 109: 19-45.

Wheelwright, N.T, Dukeshire, E.E., Fontaine, J.B., Gutow, S.H., Moeller, D.A., Schuetz, J.G., Smith, T.M., Rodgers, S.L., and Zink, A.G. 2006. Pollinator limitation, autogamy and minimal inbreeding depression in insect-pollinated plants on a boreal island. Am. Midl. Nat. 155: 19-38.

Winn, A.A., Elle, E, Kalisz, S., Cheptou, P.-O., Eckert, C.G., Goodwillie, C., Johnston, M.O., Moeller, D.A., Ree, R.H., Sargent, R.D., and Vallejo-Marín, M. 2011. Analysis of 
inbreeding depression in mixed-mating plants provides evidence for selective interference and stable mixed mating. Evol. 65: 3339-3359.

Zink, A.G., and Wheelwright, N.T. 1997. Facultative self-pollination in island irises. Am. Midl. Nat. 137: 72-78. 
Table 1. Influence of hand-pollination treatments on survivorship at key life-history stages and measures of growth and physiology in Iris versicolor on Kent Island, New Brunswick, Canada.

\begin{tabular}{|c|c|c|c|c|}
\hline Trait & $\mathrm{N}$ & $\begin{array}{c}\text { Treatment } \\
\left(\chi^{2}, \text { d.f. }=3\right)\end{array}$ & $\begin{array}{c}\text { Site } \\
\left(\chi^{2}, \text { d.f. }=1\right)\end{array}$ & $\begin{array}{l}\text { Treatment } \times \text { Site } \\
\qquad\left(\chi^{2}, \text { d.f. }=3\right)\end{array}$ \\
\hline Proportion of flowers that set fruit & 800 flowers & 0.044 & 0.074 & 0.131 \\
\hline Number of seeds per capsule & 549 capsules & $<0.001$ & 0.411 & 0.395 \\
\hline Proportion of seeds matured & 549 capsules & $<0.001$ & 0.591 & 0.093 \\
\hline Proportion of seeds germinated & 142 capsules & 0.887 & 0.349 & 0.707 \\
\hline Capsule length & 551 capsules & $<0.001$ & 0.139 & 0.403 \\
\hline Seed size & 521 capsules & 0.001 & 0.311 & 0.031 \\
\hline Number of leaves ${ }^{1}$ & 60 plants & 0.397 & 0.116 & 0.758 \\
\hline Leaf length $^{1}$ & 60 plants & 0.090 & 0.750 & 0.448 \\
\hline Leaf width ${ }^{1}$ & 60 plants & 0.157 & 0.709 & 0.211 \\
\hline Leaf thickness ${ }^{1}$ & 60 plants & 0.308 & 0.651 & 0.736 \\
\hline Effective quantum yield $\left(\Phi_{\mathrm{PSII}}\right)^{1}$ & 60 plants & 0.514 & 0.072 & 0.718 \\
\hline Maximum quantum yield $\left(\mathrm{F}_{\mathrm{v}} / \mathrm{F}_{\mathrm{m}}\right)^{1}$ & 61 plants & 0.201 & 0.924 & 0.128 \\
\hline
\end{tabular}

${ }^{\mathrm{T}}$ traits measured in $\mathrm{F}_{1}$ plants grown in the greenhouse

$\mathrm{N}$ refers to overall sample size. Values are $p$-values based on sequential fixed effects likelihood ratio tests comparing models fit using maximum likelihood and linear mixed effects or generalized linear mixed effects (Poisson distribution: number of leaves per plant; binomial 
distribution: proportion of flowers that set fruit, seeds matured, and seeds germinated). Random effects were treatment $\times$ clone and clone (or, in greenhouse experiments, block). 
Table 2. Geographic characteristics of study sites and summary of population genetic diversity and divergence for 13 island populations and three mainland populations of Iris versicolor in the Bay of Fundy.

\begin{tabular}{|c|c|c|c|c|c|c|}
\hline Population & Code & $\begin{array}{l}\text { Area of } \\
\text { island } \\
\left(\mathrm{km}^{2}\right)\end{array}$ & $\begin{array}{l}\text { Distance } \\
\text { from } \\
\text { mainland } \\
(\mathrm{km})\end{array}$ & $\begin{array}{l}\text { Percent } \\
\text { polymorphic } \\
\text { fragment } \\
\text { lengths }\end{array}$ & $\begin{array}{l}\text { Mean no. } \\
\text { alleles per } \\
\text { primer pair }\end{array}$ & $\begin{array}{l}\text { Pairwise } \\
\text { genetic } \\
\text { distance }\end{array}$ \\
\hline Black's Harbour & $\mathrm{BH}$ & - & 0 & 70.59 & 8.7 & 0.025 \\
\hline $\begin{array}{l}\text { Campobello } \\
\text { Island }\end{array}$ & $\mathrm{CA}$ & - & 0 & 67.65 & 8.7 & 0.026 \\
\hline Cutler, Maine & $\mathrm{CU}$ & - & 0 & 79.41 & 9.7 & 0.022 \\
\hline $\begin{array}{l}\text { Grand Manan } \\
\text { (north) }\end{array}$ & GMN & 142.17 & 13.2 & 47.06 & 6.3 & 0.025 \\
\hline $\begin{array}{l}\text { Machias Seal } \\
\text { Island }\end{array}$ & MS & 0.09 & 17.3 & 58.82 & 7.0 & 0.053 \\
\hline $\begin{array}{l}\text { Grand Manan } \\
\text { (east) }\end{array}$ & GMT & 142.17 & 20.6 & 64.71 & 7.7 & 0.020 \\
\hline Wood Island & WO & 2.15 & 22.1 & 61.76 & 7.7 & 0.018 \\
\hline Outer Wood & OW & 0.60 & 24.3 & 67.65 & 8.0 & 0.027 \\
\hline Island & & & & & & \\
\hline Inner Green & GRN & 0.04 & 26.6 & 61.76 & 7.3 & 0.018 \\
\hline
\end{tabular}




\begin{tabular}{|c|c|c|c|c|c|c|}
\hline Outer Green & GRS & 0.03 & 27.9 & 55.88 & 7.0 & 0.024 \\
\hline \multicolumn{7}{|l|}{ Island } \\
\hline Hay Island & $\mathrm{H}$ & 0.24 & 28.3 & 55.88 & 7.0 & 0.025 \\
\hline Whitehead Island & WH & 6.06 & 28.7 & 70.59 & 8.3 & 0.015 \\
\hline Kent Island & $\mathrm{KN}$ & 1.00 & 28.7 & 55.88 & 7.3 & 0.024 \\
\hline \multicolumn{7}{|l|}{ (north) } \\
\hline Sheep Island & $\mathrm{S}$ & 0.12 & 29.1 & 61.76 & 7.7 & 0.021 \\
\hline Kent Island (west) & $\mathrm{KW}$ & 1.00 & 29.7 & 52.94 & 7.0 & 0.026 \\
\hline Kent Island & KS & 1.00 & 30.4 & 58.82 & 7.3 & 0.026 \\
\hline
\end{tabular}

Campobello Island was considered a mainland site because of its proximity to the mainland, connection via bridge, and large size. All sites are located in New Brunswick, Canada except Cutler, which is in Maine (see Fig. 1). Sites are listed in order of distance from the nearest mainland. Percent polymorphic fragment lengths is the average percentage across primer pairs of fragment lengths that are not fixed within a population. Mean no. alleles per primer pair is the average of the number of distinct fragment lengths per primer pair found in a sample of 20 individuals. Pairwise genetic distance is mean pairwise Nei's unbiased genetic distance. 
FIGURE CAPTIONS

Fig. 1. Locations of sampled populations of Iris versicolor in the Bay of Fundy. Inset shows island populations around Grand Manan Island. Kent Island, where all hand-pollination experiments were carried out in three different sites $(\mathrm{KN}, \mathrm{KW}, \mathrm{KS})$, is the southernmost island in the inset and is located c. $9 \mathrm{~km}$ from Grand Manan. Kent and Hay (H) Islands are connected at low tide, and one can walk to adjacent Sheep (S) Island at extreme low tide. See Table 2 for explanation of codes for the other sites and distance to the mainland. Base map from the US National Oceanic and Atmospheric Administration (http://www.ngdc.noaa.gov/mgg/shorelines/shorelines.html).

Fig. 2. Effects of inbreeding and outbreeding on fruit and seed traits of Iris versicolor from two sites on Kent Island, New Brunswick (South, West Beach). Open-pollinated control plants were compared with experimental crosses (inbreeding, within-site outbreeding, between-island outbreeding). Figures show least squares means $\pm 95 \%$ CI for: (a) proportion of hand-pollinated and control flowers that set fruit $(\mathrm{N}=88-106$ flowers per treatment $\times$ site combination, 65 clones, 800 flowers); (b) capsule (fruit) length (59-84 capsules per treatment $\times$ site combination, 64 clones, 551 capsules); (c) total number of seeds per capsule (59-84 capsules per treatment $\times$ site combination, 64 clones, 549 capsules); (d) proportion of seeds per mature capsule (59-84 fruits per treatment $\times$ site combination, 64 clones, 549 capsules $)$; (e) mean seed size $(\mathrm{N}=53-81$ capsules per treatment $\times$ site combination, 64 clones, 521 capsules); and (f) proportion of seeds that germinated (10-26 seeds per treatment $\times$ site combination, 23 clones, 142 seeds). 
Fig. 3. Effects of inbreeding and outbreeding on photosynthetic efficiency and size of $\mathrm{F}_{1}$ Iris versicolor plants originating from two sites on Kent Island, New Brunswick (South, West Beach) and grown under common conditions in a greenhouse. Open-pollinated control plants were compared with experimental crosses (inbreeding, within-site outbreeding, between-island outbreeding). Figures show least squares means $\pm 95 \% \mathrm{CI}$ for: (a) $\mathrm{F}_{\mathrm{v}} / \mathrm{F}_{\mathrm{m}}$ (which measures the capacity of photosynthetic machinery to absorb light); (b) $\Phi_{\text {PSII }}$ (which measures the efficiency with which absorbed light is utilized in photosynthesis); (c) number of leaves; (d) length of longest leaf; (e) width of longest leaf at midpoint; (f) thickness of longest leaf at midpoint.

Fig. 4. Genetic diversity of sampled populations of Iris versicolor as a function of distance from the mainland. Percent polymorphic fragments is the average percentage across primer pairs of fragment lengths that are not fixed within a population. 


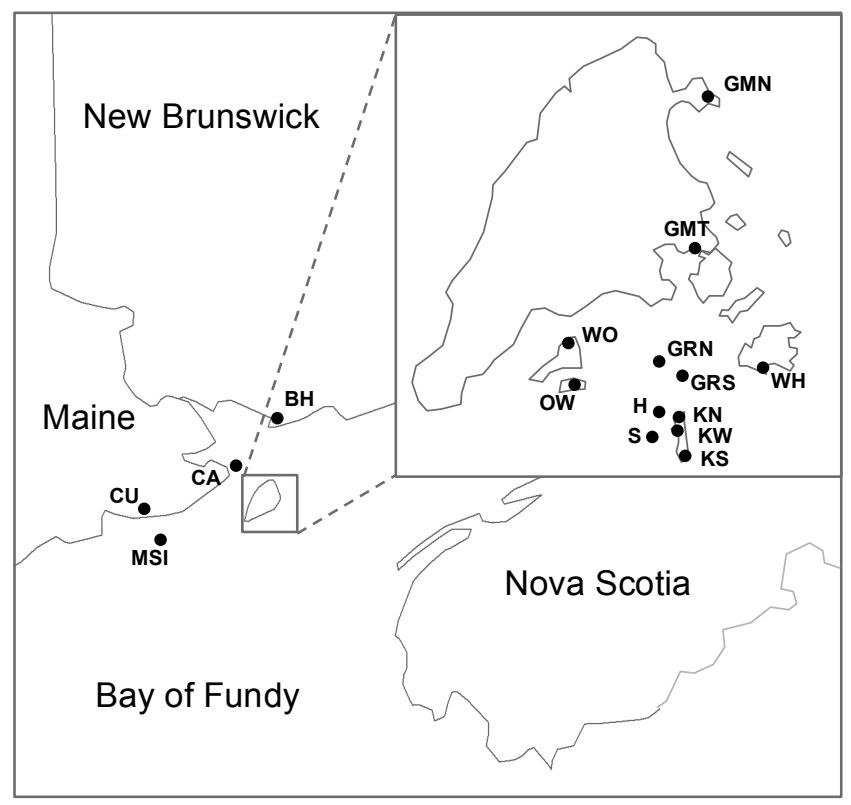

https://mc06.manuscriptcentral.com/botany-pubs 


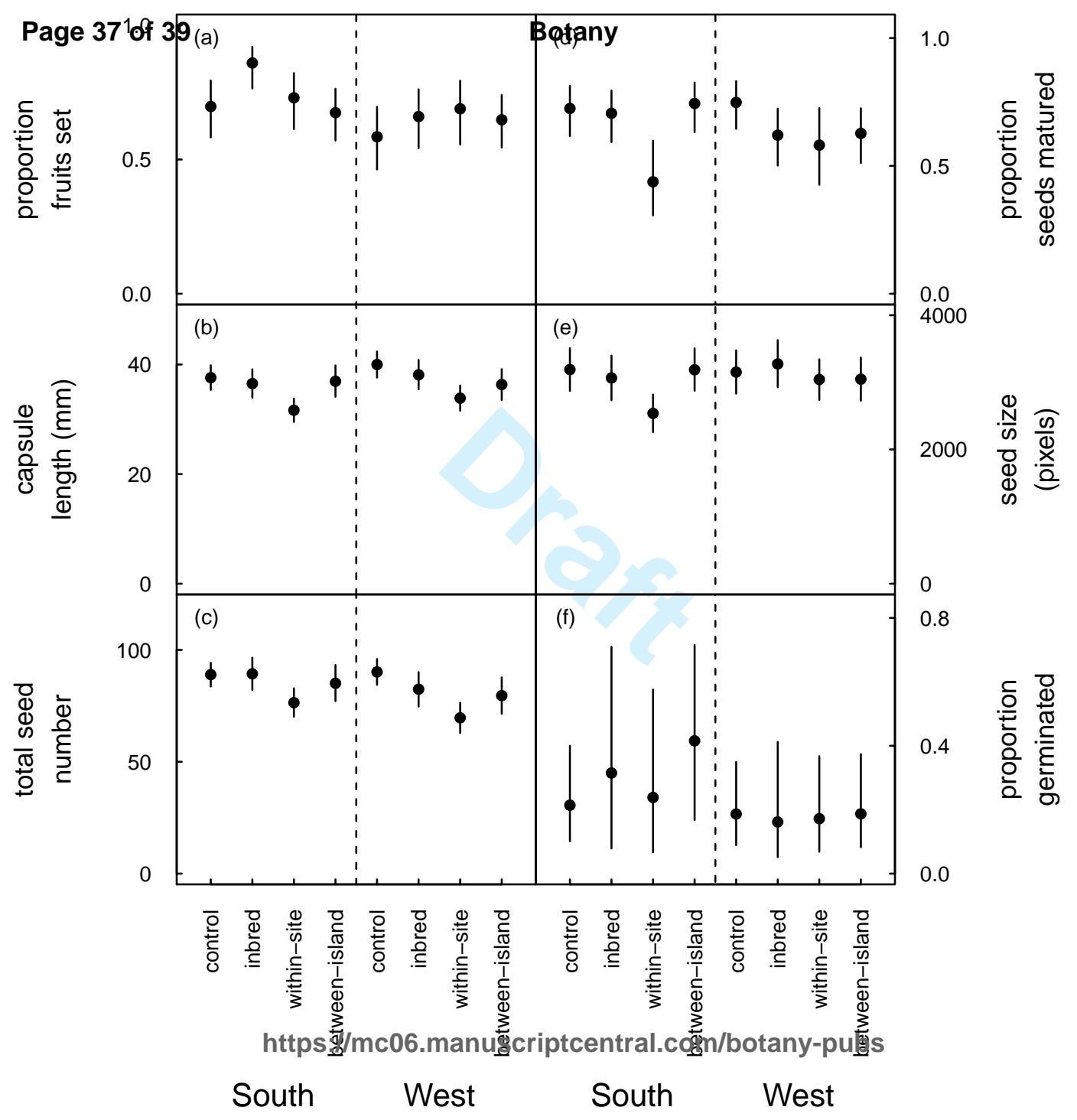




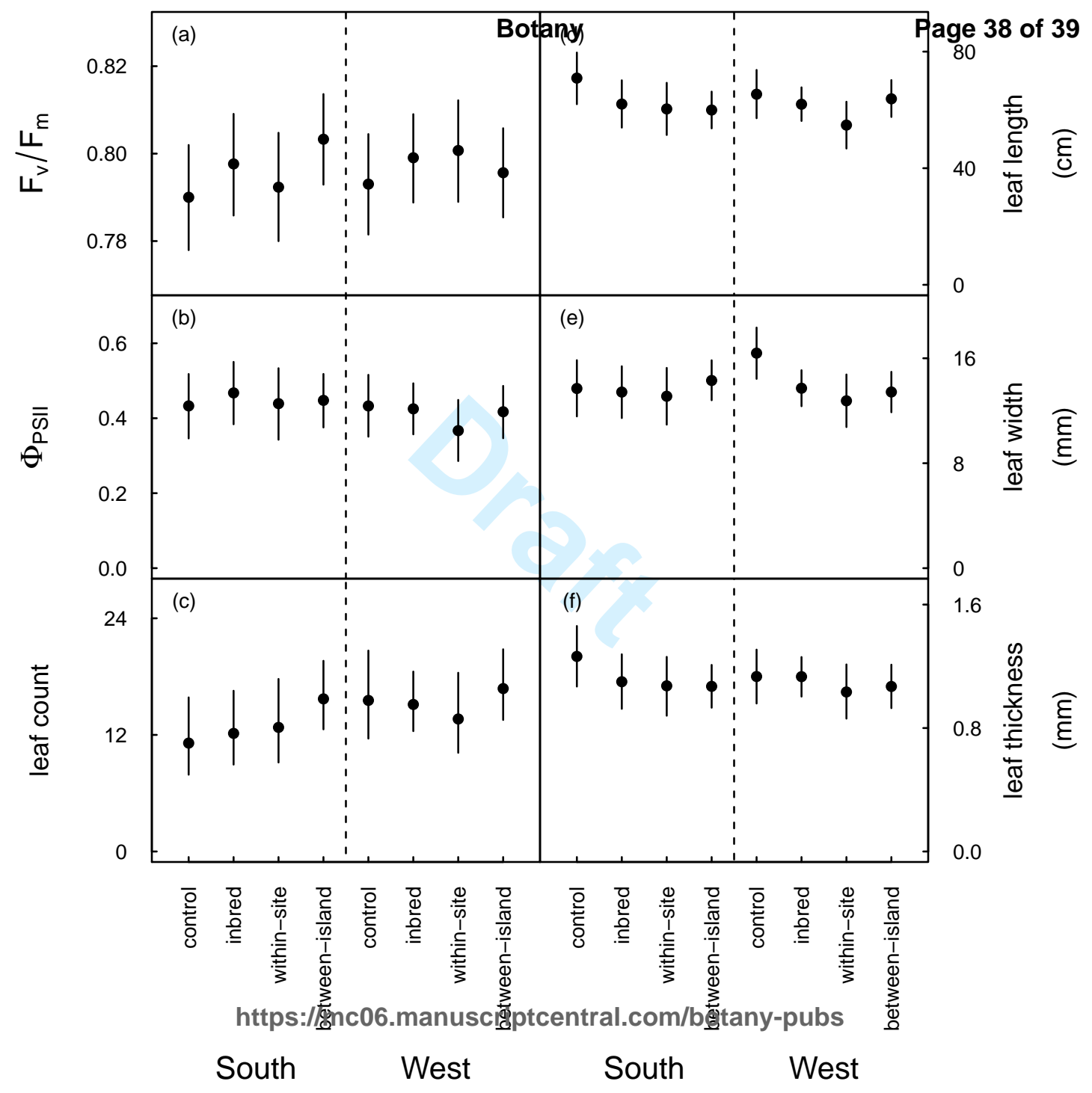




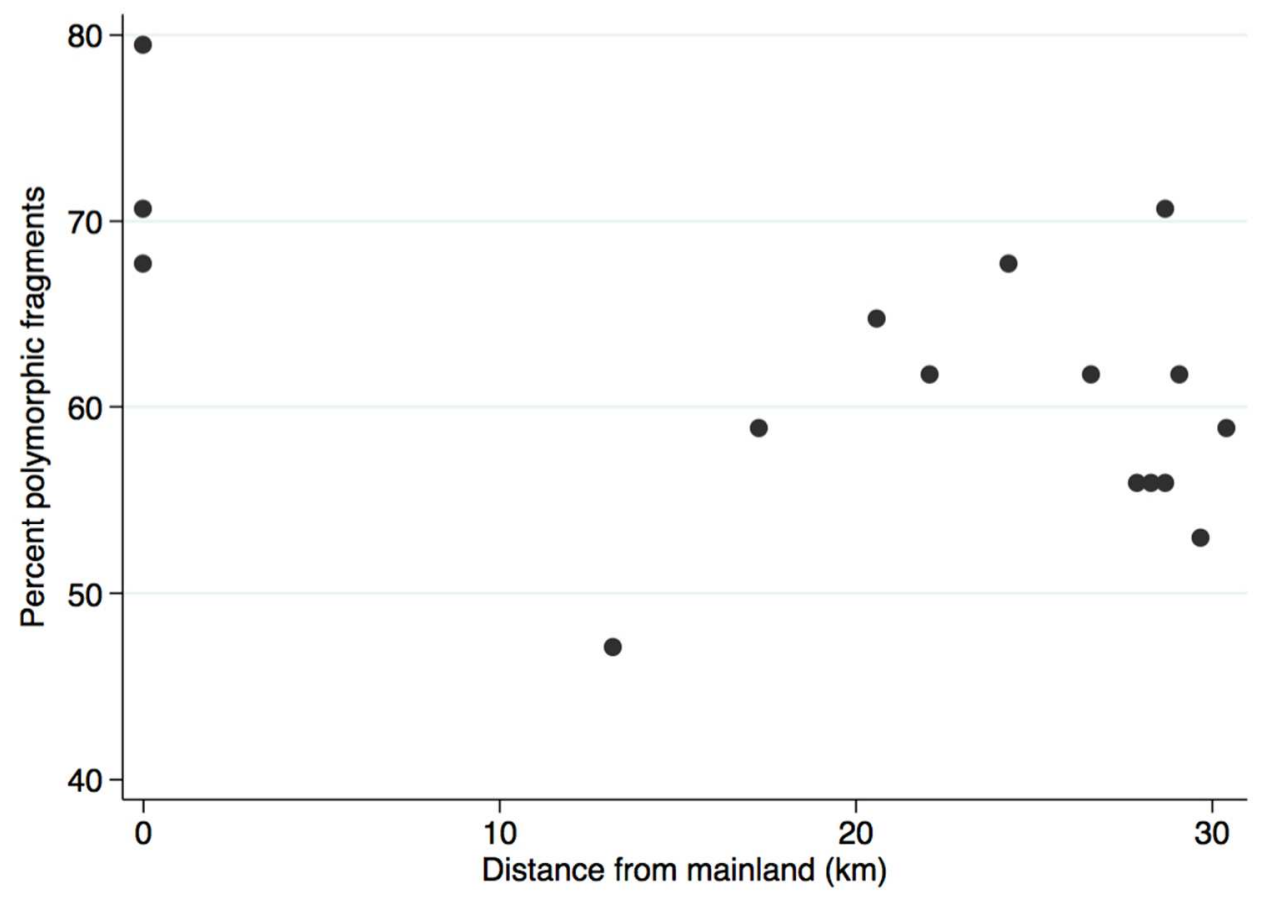

$390 \times 283 \mathrm{~mm}(72 \times 72 \mathrm{DPI})$ 